\title{
CONCEPÇÃO DE MULHERES SOBRE O CLIMATÉRIO E O USO DE PLANTAS MEDICINAIS COMO TERAPÊUTICA NATURAL
}

\section{OPINION OF WOMEN ABOUT CLIMACTERIC AND THE USE OF MEDICINAL PLANTS AS NATURAL THERAPY}

\section{Ana Paula Silva dos Anjos ${ }^{1} *$ Zulmerinda Meira Oliveira $^{2} *$ Octavio Muniz da Costa}

\author{
$\operatorname{Vargens}^{3}$ * Jane Márcia Progianti ${ }^{4}$
}

\section{RESUMO}

Objetivo: Identificar a concepção de climatério e quais as plantas medicinais mais utilizadas como terapêutica natural por mulheres que o vivenciam. Método: Estudo qualitativo, descritivo e exploratório. Teve como participantes 17 mulheres maiores de 40 anos que estavam frequentando assiduamente a uma Unidade Básica de Saúde de um município da Bahia e que atenderam aos critérios de exclusão e inclusão. A coleta dos dados se deu por meio da entrevista semiestruturada. O estudo foi aprovado pelo Comitê de Ética em Pesquisa da Universidade Estadual do Sudoeste da Bahia, conforme parecer $n^{\circ} 2.440 .117$. Os dados foram analisados por meio da técnica de Análise de Conteúdo Temática de Bardin. Resultados: A partir da aplicação do método de análise, originaram-se, em conformidade com o objetivo deste estudo, duas categorias temáticas. Categoria 1 confundindo climatério com menopausa e considerando-o como doença e a Categoria 2 identificando as plantas medicinais como terapêutica natural para as mudanças inerentes ao climatério, o estudo ainda apontou que as mulheres confundem o climatério com menopausa, considera-o como doença e recorre ao uso de plantas medicinais como terapêutica natural. Conclusão: $O$ estudo evidenciou que as participantes têm uma concepção equivocada a respeito do climatério, todavia sabem identificar as modificações próprias da fase e utilizam estratégias de práticas integrativas como terapêutica natural para o enfrentamento dessa fase da vida.

Palavras-chave: Climatério; Plantas Medicinais; Saúde da Mulher; Terapêutica.

\section{ABSTRACT}

Objective: Identifying the opinion of climacteric and which medicinal plants are most used as natural therapy by women who experience it. Method: A descriptive, exploratory and qualitative study. Participants were 17 women over 40 who were attending a Basic Health Unit in a municipality of Bahia and who met the exclusion and inclusion criteria. Data were collected through semi-structured interviews. The study was approved by the Research Ethics Committee of the State University of Southwest Bahia, according to Opinion N 2,440,117. The data were analyzed using Bardin's Thematic Content Analysis technique. Results: From the application of the analysis method, two thematic categories originated, in accordance with the objective of this study. Category 1 confusing climacteric with menopause and considering it as a disease and Category 2 identifying medicinal plants as natural therapy for the changes inherent to climacteric, the study also pointed out that women confuse climacteric with menopause, consider it as a disease and use medicinal plants as natural therapy. Conclusion: The study showed that the participants have a mistaken conception about the climacteric; however, they know how to identify the changes specific to the phase and use strategies of integrative practices as natural therapy to cope with this phase of life.

Keyword: Climacteric; Medicinal Plants; Women's Health; Therapeutics.

\footnotetext{
${ }^{1}$ Enfermeira. Graduada pela Universidade Estadual do Sudoeste da Bahia. Orcid: https://orcid.org/0000-0002-8051-3687. E-mail: anapsanjos25@gmail.com

${ }^{2}$ Enfermeira. Professora Adjunta da Universidade Estadual do Sudoeste da Bahia. Orcid: https://orcid.org/0000-0002-6652-2229. Email: zulmerinda.meira@uesb.edu.br

${ }^{3}$ Enfermeiro. Professor Titular da Universidade do Estado do Rio de Janeiro. Orcid: https://orcid.org/0000-0002-8051-3687. E-mail: omcvargens@uol.com.br

${ }^{4}$ Enfermeira. Professora Titular da Universidade do Estado do Rio de Janeiro. Orcid: https://orcid.org/0000-0002-8051-3687. E-mail: jmprogi@gmail.com
} 


\section{INTRODUÇÃO}

Este estudo aborda a concepção de climatério e o uso de plantas medicinais como terapêutica natural por mulheres que $\mathrm{o}$ vivenciam e que frequentam um serviço de prevenção do câncer de colo uterino em uma unidade da Estratégia de Saúde da Família (ESF).

O climatério é um termo comumente utilizado como sinônimo de menopausa, porém esse último é um fenômeno que se define retroativamente, representando a cessação permanente das menstruações por um período de 12 meses ${ }^{(1)}$. O termo climatério vem de origem grega (klimakter), ao fazer menção ao topo de uma escada, ao se referir ascensão a um diferente estágio da vida (2). A Organização Mundial da Saúde (OMS) define climatério como uma fase biológica e não patológica da vida da mulher, além de compreender esse processo como uma transição da fase reprodutiva para a não reprodutiva ${ }^{(2-3)}$.

Já o termo menopausa vem também do grego e se refere a mens $=$ mês e pausis $=$ pausa, no entanto compreende a interrupção das menstruações ${ }^{(2)}$. Sendo a menopausa caracterizada como a parte final da fase reprodutiva que corresponde ao último ciclo menstrual e geralmente acontece entre 48 e 50 anos de idade ${ }^{(1)}$.

Todavia, ao compreender que o climatério não é uma doença, e sim uma fase natural da vida da mulher, e que muitas delas podem passar por essa fase sem apresentar queixas ou necessidade de medicalização, outras podem apresentar transformações no seu organismo que variam na sua diversidade e intensidade ${ }^{(1)}$, e isso vai depender de como cada mulher vai encarar esse processo do corpo envelhecendo.

Nessa perspectiva, envelhecer com qualidade surge como esperança mesmo que em uma sociedade marcada pela cultura do repúdio à velhice. A compreensão de que a maturidade também inclui autoconhecimento e aceitação e de que na velhice há um processo maior de investimento no autoconhecimento, gerando modos mais positivos de apreciação da vida, o que pode resultar em uma transformação dos estereótipos negativos sobre o envelhecimento do ponto de vista social ${ }^{(2-4)}$.

Os tabus relacionados ao climatério se devem à forma de como esse processo é abordado, muito difundido com conotações negativas, utilizando termos como falência, atrofia, perda, entre outras denominações que caracterizam algo ruim. Nesse sentido, a mulher passa a optar por se submeter à hormonioterapia por acreditar que o climatério é uma doença, no entanto ela precisa perceber que o climatério é uma fase da vida e que é possível contorná-lo por meio de práticas e terapêuticas integrativas complementares, além dos fitoestrogênios e os moduladores seletivos de receptores de estrogênio, não havendo necessidade de introduzir a "medicalização" como terapêutica (1-5). 
Nessa perspectiva, a medicalização envolve processos mais vastos que não se limitam apenas ao produto medicamento, além de possuir uma lógica mais sutil e perversa do controle da vida das pessoas e da sociedade ${ }^{(5-6)}$. Assim, o termo medicalização tem sido empregado como o processo de transformação dos aspectos da vida cotidiana em objetos da medicina, esquematizando a conformidade e as normas sociais.

Assim, a medicalização permeia pela lógica das normas sociais estabelecidas pela medicina tradicional, como processo de modificação na vida das pessoas. E pensando em romper com esse paradigma, no ano de 2006 a partir de várias conferências nacionais de saúde e das recomendações da Organização Mundial da Saúde (OMS) foi institucionalizada no Brasil a Política Nacional de Práticas Integrativas e Complementares (PNPIC) como elemento do Sistema Único de Saúde (SUS) ${ }^{(7)}$.

Considerando que os serviços de saúde na maioria são frequentados por mulheres, e que esta mulher pode ser vista na sua dimensão global, sem perder de vista a sua singularidade, seus processos de viver em qualquer fase da vida. Nesse contexto, a PNPIC contempla a integralidade da atenção à saúde da mulher na fase do climatério. Fase esta, que requer também a interação de outras ações existentes no SUS. Esta interação contribui para a ampliação da corresponsabilidade e autonomia da mulher pela sua saúde na perspectiva desmedicalizada, durante esse período aumentando assim, o exercício da sua cidadania e consequentemente sua qualidade de vida ${ }^{(7)}$ Ademais, é preciso romper com o paradigma de que climatério tem que ser tratado com hormonioterapia e impulsionar ações contra a hegemonia e a medicalização e colocar a mulher como protagonista $\mathrm{e}$ autônoma do cuidado consigo mesma.

No campo da saúde, a Política Nacional de Práticas Integrativas e Complementares contempla as diretrizes e responsabilidades institucionais para a oferta de serviços e produtos diversos, bem como a utilização de plantas medicinais como possibilidades terapêuticas (6) para o enfrentamento das alterações intrínsecas do climatério, garantindo assim maior integralidade $\mathrm{e}$ resolutividade da atenção à saúde da mulher durante essa fase.

Vale ressaltar, que a PNPIC contempla na sua estrutura temas transversais que podem estar presentes em todos os pontos da Rede de Atenção à Saúde, prioritariamente na Atenção Primária com amplo potencial de atuação nas ações determinadas pelo SUS. As abordagens principais desse campo perpassam pela visão ampliada da prevenção e da promoção global do cuidado humano, especialmente do autocuidado e da autonomia. E se tratando da mulher que vivencia o climatério, este cuidado é embasado em seus múltiplos aspectos biopsicossocial, cultural e espiritual.

$\mathrm{O}$ uso de plantas medicinais na arte de curar é uma forma de terapêutica de origem 
muito antiga, relacionada aos primórdios da medicina e fundamentada no acúmulo de informações por gerações. Ao longo dos séculos, produtos de origem vegetal constituíram as bases para tratamento de diferentes alterações no organismo ${ }^{(7)}$.

Nesse contexto, o uso de chás com plantas medicinais influencia na melhora das diversas modificações corporais apresentadas por muitas mulheres durante a fase do climatério. E foi mostrado nesse estudo que as participantes buscaram essa alternativa terapêutica nas práticas integrativas complementares. As plantas medicinais são aquelas capazes de aliviar ou curar enfermidades e ou características peculiares a uma determinada situação e têm tradição de uso como remédio em uma população ou comunidade $^{(8)}$ Enquanto que a OMS define planta medicinal como sendo toda e qualquer planta que possui, em um ou mais órgãos, substâncias que podem ser utilizadas com fins terapêuticos ${ }^{(2)}$.

O Brasil possui grande potencial para o desenvolvimento dessa terapêutica, com a maior diversidade vegetal do mundo, ampla sociodiversidade do uso de plantas medicinais vinculado ao conhecimento tradicional e tecnologia para validar cientificamente esse conhecimento.

Sendo assim, este estudo justifica-se pelo fato da necessidade de divulgar quanto ao o uso de plantas medicinais por mulheres que vivenciam o climatério, além de trazer uma relevância social significativa e contribuir não somente com os profissionais da área de saúde e acadêmicos, mas também com as mulheres que estiverem vivenciando a fase do climatério. Considerando que há uma escassez de estudos que versam sobre a temática, este pode colaborar com mudanças de hábitos e estilo de vida de diversas mulheres no processo do climatério ao agregar parte das práticas integrativas complementares em saúde, como exemplo as plantas medicinais.

Nessa perspectiva, elaborou-se a questão norteadora como uma preocupação que remete a compreensão significativa de respostas por meio do objetivo do estudo. Qual a concepção de climatério de mulheres que o vivenciam e quais plantas medicinais utilizam como terapêutica natural desse processo?

Tal questionamento suscitou a construção do seguinte objetivo: Identificar a concepção de climatério por mulheres que o vivenciam e quais plantas medicinais utilizam como terapêutica natural desse processo.

\section{MÉTODO}

Trata-se de um estudo de cunho qualitativo, descritivo e exploratório cuja amostragem foi aleatoriamente constituída por 17 mulheres que frequentavam o serviço de prevenção de câncer de colo uterino de uma unidade da Estratégia Saúde da Família (ESF) situada no interior da Bahia. As participantes atenderam aos seguintes critérios de inclusão ter idade maior que 40 anos e 
estarem frequentando assiduamente a unidade. E como critérios de exclusão, apresentar deficit cognitivo que implicasse na coleta das informações e deficiência auditiva que impedisse ou dificultasse na comunicação verbal. A coleta foi interrompida ao perceber repetições das informações, o que se caracterizou como processo de saturação dos dados.

O cenário do estudo foi a unidade da ESF. A coleta das informações aconteceu mediante aprovação pelo Comitê de Ética em Pesquisa (CEP) da Universidade Estadual do Sudoeste da Bahia conforme parecer de número 2.440.117 no ano de 2019. Utilizouse como instrumento um roteiro de entrevista semiestruturada, previamente elaborada com perguntas objetivas e subjetivas contendo dados sociodemográficos e deixando as participantes à vontade para responder aos questionamentos.

As entrevistas duraram em média 30 minutos e foram realizadas individualmente na sala de espera da (USF), após esclarecimentos sobre o objetivo e procedimentos do estudo de acordo a disponibilidade das participantes e assinatura do Termo de Consentimento Livre e Esclarecido (TCLE). Por se tratar de um estudo envolvendo seres humanos, respeitouse as diretrizes e normas regulamentadoras instituídas por meio da Resolução no 466/12 do Conselho Nacional de Saúde (CNS) ${ }^{(9)}$.

O tratamento e a análise dos dados se deram mediante a técnica de análise de conteúdo temática de Bardin ${ }^{(10)}$. Diante da diversificação e também aproximação terminológica, optou-se por elencar as etapas em três fases: 1) Pré-análise; 2) Exploração do material; e 3) Tratamento dos resultados, inferência e interpretação. Assim, este estudo culminou com as fases preconizadas por Bardin ${ }^{(10)}$. Iniciou-se a primeira fase pela préanálise, na qual foi organizado todo o material analisado com o objetivo de torná-lo operacional, sistematizando as ideias iniciais. Posteriormente, houve a exploração do material que se constituiu na segunda fase, a análise dos dados, buscando a identificação das unidades de registro e, consequentemente, a definição de categorias. Na terceira fase, ocorreu o tratamento dos resultados, inferência e interpretação. Nessa etapa que se deu a condensação e o destaque das informações para análise, culminando nas interpretações inferenciais, além de ser o momento da intuição, da análise reflexiva e crítica para fins teóricos e programáticos.

\section{RESULTADOS}

Inicialmente estarão apresentadas as características sociodemográficas das participantes e em seguida, as categorias.

Quanto às características sociodemográficas, observou-se que das 17 participantes a idade variou entre 40 e média de 50 anos, oito se consideraram negras, e seis se autodeclararam pardas. No que diz respeito à condição marital, dez referiram 
estar casadas. No que tange à profissão, doze eram secretárias do lar. Enquanto à religião, nove informaram ser protestantes e oito católicas. O nível de escolaridade, onze mencionaram ensino fundamental incompleto.

A partir da aplicação do método de análise, originaram-se em conformidade com o objetivo deste estudo duas categorias temáticas que se seguem.

\section{Categoria 1- Confundindo climatério com menopausa e considerando-o como doença}

A categoria acima originou-se do questionamento realizado às participantes de qual era a sua concepção sobre o climatério. No entanto, várias das participantes deste estudo referiram não conhecer ou não saber nada sobre esta fase da vida da mulher. Observem nos seus depoimentos.

Ah! Climatério é. Eu não sei. Não entendo disso não (risos). Eu não sei muito disso não. (P3)

É o que eu te falei, não entendo nada disso aí [risos]. (P4)

Nunca ouvi falar. (P6

Rapaz, eu [risos]... o climatério? Já ouvi, mas eu tô vagando agora. (P11)

Climatério? Não. (P13)

Provavelmente nada, né [risos]. Não tenho conhecimento não. (P15)

Eu quero aprender agora, porque eu não sei [risos]. Bom que eu aprendo né? (P16)
No entanto, apesar de elas relatarem que não sabem ou não conhecem o que é o climatério, elas reconhecem e descrevem com detalhes as características peculiares dessa fase que estão vivenciando, porém ainda veem como sintomas, e relatam que apresentam, sudorese, calor, frio fogacho, insônia, nervoso, esquecimento entre outras características e/ou confundem com a menopausa, evidenciando as dificuldades de entendimento do fenômeno.

Mas aí é o sintoma da menopausa que fala né? Eu só sei assim, que eu mesma, digo de mim, eu senti muito calor, minha menstruação foi embora com 47 anos, aî eu fui ao médico, ele disse que era normal porque era menopausa, aí comecei o tratamento e fiquei boa. (P1)

O climatério é quando você determina que a menstruação não existe mais, que também às vezes sente algumas queixas, como calor, insônia, sua muito a noite como às vezes, eu mesma senti nervoso, eu senti insônia, preocupação esquecimento. (P9)

Eu sei pouca coisa né, mas é que nesse período a mulher fica começando a ter aquelas ondas de calor né, inclusive eu já tô começando a sentir, já sinto um calor estranho. E que essa menopausa tem mulheres que é mais tarde, tem mulheres que é mais cedo. (P14)

Eu sei também assim que a menstruação diminui né, mas no meu caso foi diferente que aumentou. E assim, eu não sei se é por causa da perda de sangue ou se é por causa da menopausa que eu tô sentindo assim fraqueza, eu não sei se é hormônio que perde, eu não sei, o que eu sei é que tô assim. E o que eu entendo desse climatério é isso, é que a mulher perde hormônio né, dizem que perde muito hormônio. Tem umas que precisam 
tomar hormônio né? Eu sei muito pouco sobre isso aí. (P14)

Eu sabia da menopausa, mas isso aí que você falou agora eu não sabia não né. (P16)

E calor, frio, calor... Tirava a coberta era um frio, daí é coberta, é blusa. ah eu me lembro. (P17)

\section{Categoria 2- Identificando as plantas medicinais como terapêutica natural para as mudanças inerentes ao climatério}

A categoria 2 aponta quais as plantas medicinais as participantes buscaram como terapêutica natural para auxiliar no enfrentamento das modificações inerentes ao climatério. Nos seus depoimentos fica claro a utilização de diversos chás como por exemplo o chá de amora, coentro, salsinha, hortelã, erva-cidreira, capim santo, espinheira santa e outras ervas que se encontram contemplados nas Práticas Integrativas Complementares em Saúde. Tais estratégias, foram utilizadas com a finalidade de aliviar e ou minimizar as mudanças próprias dessa fase da vida.

Eu curei mais com chazinho. (P1)

Uso folha de amora, aí eu cozinho e tomo. (P3)

Eu tomo coentro com salsinha, hortela grosso, erva-cidreira, capim santo. Misturo todos junto e tomo... Tem uma também que minha mãe sempre me ensinava, é um tipo de semente, “mulungu” parece. (P5)

Oh minha filha, foi tanto chá. Chá de amora, chá de espinheira santa, tanto chá que eu tomo que tu nem imagina. (P8)
Eu tomei muito chá, sabe chás de amora, espinheira santa, capim santo, assim, sempre nós tomávamos chás, lá na roça a gente tomava muito chá, e aí eu sempre tomo, até hoje tomo. (P9)

Só chá. Chá de amora, esses chazinhos assim. Coisa homeopática, fitoterápicos coisas mais naturais, sabe? (P11)

Eu tomo bastante chá da amora, como aveia, soja, aí comecei a pesquisar, encontrei esse chazinho de amora $e$ vários outros chazinhos que tem, né, camomila, mas eu tomo mesmo é o chá de amora (P14)

$E$ É eu usava chá muito assim, de ervacidreira, capim santo, capim-cidreira. (P17).

\section{DISCUSSÃO}

A primeira categoria nos remete ao entendimento que as participantes deste estudo têm uma concepção ainda equivocada de climatério. Embora, mais da metade dos usuários que frequentam a Atenção Primária é composto por mulheres ${ }^{(1-3)}$. Isso nos faz refletir que pode haver uma deficiência de saberes e práticas, principalmente por parte dos profissionais que atuam nos diversos serviços de saúde. Nesse sentido, as mulheres para suprir com suas necessidades sentidas, buscam o cuidado dos profissionais de saúde inseridos neste contexto. Desse modo, a política de saúde da mulher oferece-lhe o direito de se ver na sua integralidade como sujeito autônomo e participativo no processo de decisão para o autocuidado. Assim, à medida que ela é incluída nesse processo, há a garantia do atendimento de suas necessidades 
e da qualidade do cuidado principalmente nos serviços de saúde ${ }^{(11)}$.

Nessa perspectiva, reitera-se a necessidade de os profissionais de saúde que atuam nesses espaços a exemplo dos enfermeiros/as, médicos/as assistentes sociais, psicólogos/as e o Agente Comunitário de Saúde-ACS e demais profissionais estarem abertos para acolher e atender as necessidades sentidas da mulher que vivencia o climatério, visando assim proporcionar-lhe conhecimento do seu próprio corpo em relação as modificações inerentes desta fase: a insônia, a sudorese, o fogacho a perda da libido, queda do cabelo, ressecamento da pele entre outras, a fim de mostrar que estas alterações fazem parte desse processo e, que isso cada mulher pode vivenciar de maneira mais natural possível contribuindo assim para uma melhor qualidade de vida ${ }^{(12)}$.

Dessa forma, é fundamental que as mulheres no climatério tenham uma assistência, ampliada e global desse processo atentando para as especificidades dessa fase. Essa assistência deve apropriar-se dos profissionais de saúde e torná-los aptos a trabalhar a subjetividade das mulheres nessa fase da vida, além de utilizar ferramentas apropriadas e mais atrativas para o momento, nas quais o profissional de saúde assume o papel de facilitador e contemple as práticas integrativas e complementares em saúde a fim de ampliar a visão de cuidado desse processo e a promoção global do cuidado humano, ${ }^{(13-14)}$ especialmente com ênfase na autonomia do autocuidado, pautado na naturalidade.

Nesse sentido, as unidades de análises da categoria 1 deste estudo representam suas concepções e revelam a escassez de informação a respeito dessa fase da vida da mulher. Talvez, o fato de muitas participantes possuírem baixo nível de escolaridade possam ter contribuído para o não conhecimento do termo climatério. Embora a maioria das usuárias frequentarem regularmente os serviços de saúde, parece ainda que o climatério é pouco abordado pelos profissionais durante as consultas. Logo, o termo menopausa é mais comum entre elas, sendo confundido com o climatério.

Em consonância com o descrito em um estudo segundo o qual as mulheres demonstravam dificuldade em discernir o sentido de climatério, referindo-se a este como sendo o mesmo que menopausa. A distinção de termos tem sua importância no sentido de identificar características inerentes às fases do ciclo da vida humana ${ }^{(3)}$.

Dessa forma, "os profissionais de saúde precisam se apropriar das múltiplas questões que abarcam o climatério para identificar, escutar e acolher essas mulheres de forma

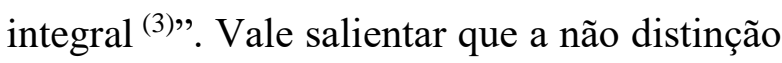
dos termos climatério/menopausa nos leva a pensar que exista ausência de informações, sobretudo em relação à terminologia científica e suas características por parte dos profissionais de saúde quando assistem a mulher nessa fase da vida. Assim, os 
profissionais de saúde devem promover com maior envolvimento uma atenção voltada para a mulher no climatério/menopausa ao saber que essas ações encontram-se preconizadas pela Política Nacional de Atenção Integral à Saúde da Mulher (PNAISM) ${ }^{(14)}$. Tal fato se torna preocupante na maioria das cidades brasileiras onde os serviços de saúde ainda não estão preparados para contemplar essa política na sua totalidade. Da mesma forma, parece haver poucos profissionais de saúde engajados e comprometidos com a valorização dessa fase da vida da mulher.

Nesse contexto, a Organização Mundial de Saúde nos mostra que o climatério não é uma doença, e sim uma fase fisiológica da vida da mulher e que muitas delas passam por essa fase sem apresentar queixas e sem necessitar de uma terapêutica medicamentosa (1-2). Tal condição nos remete à reflexão de que a medicalização do corpo feminino em nome da ciência e de um improvável bemestar sempre foi uma prática do campo da medicina e que só será transformada quando as mulheres se empoderarem e criarem estratégias de autonomia e liberdade como protagonistas do próprio cuidado consigo mesma. Assim, elas poderão definir e reconhecer seus direitos, possibilidades preventivas e de implementação de práticas naturais, bem como das consequências das distintas práticas médicas impostas sobre o seu próprio corpo.

Desse modo, vivemos em uma beleza são marcantes pela mídia ao passo em que a valorização da imagem e das aparências transformam o corpo feminino no mais belo e desejado dos objetos. Pode-se até mesmo dizer que habitamos no paradigma da corporalidade e que muitos são os aspectos que se ilustram e, com a evolução das novas tecnologias, surgem novos horizontes que colocam em evidência a dimensão do corpo feminino ${ }^{(13)}$. Afinal, o corpo não é só uma evidência, mas nele incide a essência da existência na nossa era. Nele está toda a beleza, que parece expor-se disponível a quem a cobiçar, transformando ou desfigurando o original e criando outro "produto", um modelo ideal que vai ofuscando as incompetências humanas ${ }^{(15)}$.

No processo de apropriação do corpo feminino ao longo da história, faz-se necessário dar destaque ao movimento de mulheres autônomas e desafiadoras que fizeram com que a posição de subalternidade designada ao mundo feminino em relação à medicina fosse repensada (16). Nessa perspectiva, a nossa sociedade ainda vê o corpo feminino exposto em um contexto de medicalização, além de compreender um corpo que fora construído em suas múltiplas formas de expressão. Assim, em razão da abrangência do fenômeno da medicalização, entende-se como indispensável e necessário ampliar as discussões em torno dessa temática, haja vista que ainda há uma escassez de estudos que trata desse fenômeno e diz 
respeito a uma condição que deve ser confrontada e modificada ${ }^{(16)}$.

Pressupõe-se que a medicalização também produz consequências diversas na mulher que vivencia o climatério, fato este que tem sido pouco explorado. Nesse sentido, compreende-se como importante adentrar essa temática a fim de contribuir com a construção de novas pesquisas, bem como novas reflexões críticas sobre a condição dessas mulheres que perpassam também pelo processo do envelhecimento ${ }^{(17)}$.

Identificando que não houve a diferenciação pelas mulheres deste estudo entre climatério e menopausa, é extremamente relevante que os profissionais de saúde estejam antenados para esses aspectos e coloquem as mulheres como protagonistas do seu próprio cuidado e se empoderem de autonomia para viver essa fase da vida, considerando-o como um processo natural do envelhecer feminino e que pode se pautar nas práticas integrativas para um viver mais saudável e natural.

A segunda categoria nos remete a pensar que as plantas medicinais como opção terapêutica para as mudanças intrínsecas do climatério, foram elementos que as participantes deste estudo utilizaram, e que o Ministério da Saúde aponta que a ampliação das opções terapêuticas ofertadas aos usuários do Sistema Único de Saúde (SUS), perpassa por uma garantia de acesso a diversas plantas medicinais e serviços relacionados à fitoterapia, com segurança, eficácia e qualidade, na perspectiva da integralidade da atenção à saúde ${ }^{(18)}$. Isso é importante com vistas à melhoria da atenção à saúde da população feminina em especial nessa fase da vida. Desse modo, o uso das plantas medicinais por parte das participantes deste estudo, se mostrou como importante opção de escolha para melhorar ou minimizar as alterações corporais associadas a essa fase da vida da mulher, e certamente as que estavam mais acessíveis e com respaldo nas fontes citadas para as mudanças inerentes ao climatério.

Portanto, o uso de plantas medicinais como práticas integrativas complementares em saúde na fase do climatério tornou-se uma prática de grande aceitação popular, além de envolver muitos profissionais da área da saúde ${ }^{(17)}$. Existem um crescente interesse tanto popular quanto institucional no que se refere à utilização dessas práticas no SUS. Além de existir vários documentos enfatizando a introdução de plantas medicinais e fitoterápicas no Sistema Único de Saúde ${ }^{(18)}$. Entre os principais documentos da atenção básica no SUS, destaca-se a Resolução Ciplan $N^{\circ} 8 / 88$, que regulamenta a implantação da fitoterapia nos serviços de saúde e cria procedimentos e rotinas relativas à sua implantação ${ }^{(16)}$.

Nessa perspectiva, o Ministério da Saúde, em 21 de março de 2018, altera a Portaria de Consolidação $n^{\circ}$ 2/GM/MS, de 28 de setembro de 2017, para incluir novas práticas na Política Nacional de Práticas 
Integrativas e Complementares (PNPIC) com a intenção de normatizar sua utilização no SUS e ampliar as possibilidades para garantia da integralidade na atenção à saúde. As práticas integrativas complementares no SUS são recursos, envolvendo abordagens que buscam estimular os mecanismos naturais de recuperação da saúde por meio de tecnologias eficazes, com ênfase na escuta qualificada e acolhedora, desenvolvendo o vínculo terapêutico e a integração do ser humano com o meio ambiente e suas relações sociais ${ }^{(16)}$. Nesse sentido, a ampliação da visão global do processo saúde-doença gera a valorização do autocuidado $^{(19-20)}$.

Observa-se que a população recorre a terapêutica de plantas medicinais devido à ideia popular de que o natural não traz danos, reforçando ainda mais a questão da ascensão do uso das plantas medicinais como terapêutica no climatério ${ }^{(17-20)}$. Fato este, evidente nos resultados deste estudo, quando se percebe que das 17 participantes, 10 fizeram uso das plantas medicinais como prática de terapêutica natural visando aliviar ou melhorar as alterações próprias dessa fase da vida.

O Ministério da Saúde aponta que muitas das práticas integrativas complementares estão contempladas por uma abordagem interdisciplinar de cuidado, e nos diferentes recursos terapêuticos ofertados que envolvem as substâncias como chás medicinais, emulsões de plantas, pomadas de metais ou vegetais, óleos essenciais e raízes de plantas, banho medicinal, cataplasma, compressa, enfaixamento, escalda-pés entre outras ${ }^{(18)}$.

As mulheres no climatério não sofrem de uma doença que necessita de carência ou de tratamento hormonal. A hormonioterapia deve ser entendida como uma opção terapêutica apenas para os casos em que existam indicações específicas. Assim, a medicalização do corpo feminino, com o uso contínuo de hormônios durante o climatério, tem sido uma prática comum da medicina ${ }^{(1)}$. Desse modo, é fundamental que os profissionais de saúde estejam cientificados e atualizados para procederem com uma abordagem no campo das práticas integrativas onde são reconhecidas como uma das abordagens que tem uma visão ampliada do processo natural, vez que a prática medicalizada, no futuro poderá gerar outros agravos à saúde feminina.

A expressão "medicalização" tem sido utilizada para designar o processo de transformar aspectos da vida cotidiana em objetos da medicina, de forma a assegurar conformidade às normas sociais (3). A medicalização também pode ser definida como a capacidade do saber médico de se apropriar de problemas cotidianos, revestindo, assim, de significados e explicações da medicina $^{(3)}$.

Para tanto, as PICS vêm ampliar a visão desse processo e da promoção global do cuidado humano, especialmente do autocuidado e da autonomia da mulher que 
vivencia o climatério, considerando-o em seus vários aspectos biopsicossocial na busca de uma mudança de paradigma, da lógica de intervenção focada nos sintomas para um cuidado baseado em práticas integrativas complementares. Essas práticas contribuem para a ampliação do modelo de atenção à saúde, vez que atendem a mulher na sua integralidade, singularidade e complexidade, sociocultural fortalecendo a relação entre usuário/profissional para a humanização da atenção à saúde.

\section{CONSIDERAÇÕES FINAIS}

O estudo evidencia que as participantes tem uma concepção equivocada a respeito do climatério, todavia sabem identificar as modificações próprias da fase e utilizam estratégias de práticas integrativas como terapêutica para o enfrentamento dessa fase da vida.

A contribuição e sugestões deste estudo estão pautadas na divulgação do uso das plantas medicinais por mulheres que estão vivenciando o climatério vez que elas contribuem para amenizar as modificações inerentes dessa fase. Além de incentivar a implementação/implantação de protocolos de PICs na rede de atenção à saúde, considerando que as práticas integrativas contribuem nas especificidades e particularidades dessa fase da vida, e que os serviços de saúde tenham profissionais preparados e sensibilizados em promover um cuidado à mulher durante o climatério.

Como limitação do estudo destacou-se na maioria das vezes a dificuldade de coletar as informações tendo em vista, o local de coleta e o tempo entre a entrevista e a consulta com a enfermeira da unidade de saúde, além da dificuldade destas participantes compreender o significado do termo climatério.

\section{REFERENCIAS}

1. Brasil. Ministério da Saúde. Secretaria de Atenção à Saúde - Departamento de Ações Programáticas Estratégicas. Manual de Atenção à Mulher no Climatério/Menopausa. Brasília: Editora do Ministério da Saúde [internet]. 2008 [Acesso em 18 de Agosto de 2018]; 1(9):1-192. Disponível em: http://bvsms.saude.gov.br/bvs/publicacoes/ma nual_atencao_mulher_climaterio.pdf.

2. World Health Organization [homepage na internet]. Research on the menopause in the 1990s: report of a WHO scientific group. WHO technical report series. [Acesso em 20 de Julho de 2020]. Disponível em: http://apps.who.int/iris/bitstream/10665/4184 1/1/WHO_TRS_866.pdf.

3. Bisognin P, Alves CN, Wilhelm LA, Prates LA, Scarton J, Resse LB. El climatério em la perspectiva de las mujeres [internet]. Enferm. glob. Jul 2015 [acesso em 15 de julho de 2018]; 14(39): 155-167. ISSN 1695-6141. Disponível em: http://scielo.isciii.es/scielo.php?script=sci_artt ext\&pid $=$ S1695$\underline{61412015000300008 \& \operatorname{lng}=\mathrm{es}}$

4. De Oliveira S, Santiago F, Correia A. Da velhice estigmatizada à dignidade na existência madura: novas perspectivas do envelhecer na contemporaneidade. Estudos e Pesquisas em Psicologia [Internet]. 2016 [Acesso em 23 de Julho de 2020]; 16(2): 46987. 
em: http://www.redalyc.org/articulo.oa?id=45 1851666010 .

5. Nakaoka VYES, Pereira AMO, Pereira IMO, et al. Climatério e terapia de reposição hormonal: uma revisão de literatura. Rev. Uningá.,2013; 16(1): 5-8 Disponível em: http://revista.uninga.br/index.php/uningarevie ws/article/view/1450/1066.

6. Brasil. Ministério da Saúde. Secretaria de Ciência, Tecnologia e Insumos Estratégicos. Departamento de Assistência Farmacêutica e Insumos Estratégicos. Uso de Medicamentos e Medicalização da Vida: recomendações e estratégias. [homepage na Internet] 2019; Disponível

em:http://bvsms.saude.gov.br/bvs/publicacoes Imedicamentos_medicalizacao_recomendacoe s_estrategia_led.pdf.

7. Brasil. Ministério da Saúde. Secretaria de Atenção à Saúde. Departamento de Atenção Básica. Política Nacional de Práticas Integrativas e Complementares no SUS: atitude de ampliação de acesso / Ministério da Saúde. Secretaria de Atenção à Saúde. Departamento de Atenção Básica. 2015. Disponível em: https://bvsms.saude.gov.br/bvs/publicacoes/p olitica_nacional_praticas_integrativas_comple mentares_2ed.pdf

8. Marques MAA, Lima DA, Andreotti CE, Junior AG, Lourenço ELB. Caracterização das plantas Medicinais e Medicamentos Fitoterápicos para tratamento da osteoporose utilizados no Brasil. Plantas medicinais e medicamentos fitoterápicos. Rev. Arq. Ciênc. Saúde UNIPAR, Umuarama. 2016. [Acesso em 25 de Setembro de 2021]; 20(3): 183-188. Disponível em: file:///C:/Users/Pontocom\%20Informatica/Do wnloads/5870-18973-2-PB\%20(1).pdf

9. Brasil. Ministério da Saúde. Conselho Nacional de Saúde. Comissão Nacional de Ética em Pesquisa (CONEP). Resolução $n^{\circ}$ 466, de 12 de dezembro de 2012b. Estabelece diretrizes e normas regulamentadoras de pesquisas envolvendo seres humanos. Brasília 2013. [Acesso em 20 de Março de
2020] Disponível em: http://conselho.saude.gov.br/resolucoes/2012/ Reso466.pdf.

10. Bardin, L. Análise de conteúdo. São Paulo: Edições 70; 2011.

11. Oliveira ZM, Vargens, OMC, Acioli, S, Silva SR. Nursing care in the climateric: demedicalizing perspective in primary healthcare. Journal of Nursing. 2017 [Acesso em 27 de Setembro de 2020]; 11-2. 10321043. Disponível em: https://doi.org/10.5205/1981-8963v11i2a13474p1032-1043-2017.

12.Vieira TMM, Araujo CR, Souza ECS, Costa MAR, Teston ÉF, Benedetti GMS, Marquete VF. Vivenciando o climatério: percepções e vivencias de mulheres atendidas na atenção básica. Enferm. Foco 2018 [Acesso em 24 de Setembro de 2020]; 9 (2): 40-45. Disponível em: http://revista.cofen.gov.br/index.php/enferma gem/article/view/1084.

13. Silva SB, Nery, IS, Carvalho, AMC. Representações sociais elaboradas por enfermeiras acerca da assistência à mulher climatérica na atenção primária. Rev Rene. 2016 [Acesso em 24 de Setembro de 2020]; 17(3):363-7. Disponível em: http://www.periodicos.ufc.br/rene/article/view 13469/2712.

14. Brasil. Ministério da Saúde. Secretaria de Atenção à Saúde. Departamento de Ações Programáticas Estratégicas. Política Nacional de Atenção Integral à Saúde da Mulher: Princípios e Diretrizes. Brasília: Editora do Ministério da Saúde; 2011.

15. Santos $M H$, Cerqueira $C$, Cruz RV. Abrindo a Caixa de Pandora - a Participação Política das Mulheres, as Desigualdades de Género e a Ação Positiva. Journal of Studies on Citizenship and Sustainability. 2017 [Acesso em 22 Maio de 2020]; (3): 18-40. Disponível em: https://repositorio.iscte- 
iul.pt/bitstream/10071/15487/5/Santos_Cerqu eira_\%26_Cruz_p_18_40_JSCS_3.pdf.

16. Vendreschi, LA, Ferrazza DA. Medicalização do corpo da mulher: um estudo bibliográfico sobre as estratégias de controle do feminino. $27^{\circ}$ Encontro Anual da Iniciação Cientifica 2018 [Acesso em: 23 de Setembro de 2020]. Disponível em: http://www.eaic.uem.br/eaic2018/anais/artigo s/2724.pdf.

17. Souza NLSA, Araújo CLO. Marco do envelhecimento feminino, a menopausa: sua vivência, em uma revisão de literatura. Revista Kairós Gerontologia 2015 [Acesso em 03 de junho de 2020];18(2):149165. Disponível em: https://revistas.pucsp.br/index.php/kairos/artic le/viewFile/26430/18952.

18. Brasil. Ministério da Saúde. Protocolos da Atenção Básica: Saúde das Mulheres / Ministério da Saúde, Instituto Sírio-Libanês de Ensino e Pesquisa - Brasília: Ministério da Saúde, 2016. Disponível em: http://bvsms.saude.gov.br/bvs/publicacoes/pro tocolos_atencao_basica_saude_mulheres.pdf.
19. Brasil. Ministério da Saúde. Secretaria de Atenção à Saúde. Departamento de Atenção Básica. Manual de implantação de serviços de práticas integrativas e complementares no SUS / Ministério da Saúde, Secretaria de Atenção à Saúde, Departamento de Atenção Básica 2018. Disponível em: http://189.28.128.100/dab/docs/portaldab/publ icacoes/manual_implantacao_servicos_pics.p $\underline{\mathrm{df}}$

20. Rocha BM de A, Pereira M do SV, Carneiro JQ. Terapias complementares: fitoterapia como opção terapêutica no climatério e menopausa. Rev. de Ciências da Saúde Nova Esperança. João Pessoa. 2018 [Acesso em 23 de Setembro de 2020]; 16(1): 16-25. Disponível em: http://www.facene.com.br/wpcontent/uploads/2018/05/2.-terapiascomplementares-fitoterapia-comoop\%c3\%87\%c3\%83o-terap\%c3\%8autica-noclimat\%c3\%89rio-e-menopausa.pdf.

Submissão: 2021-03-30

Aprovado: 2021-06-09 